\title{
Short communication: Automatic detection of social competition using an electronic feeding system
}

\author{
J. M. Huzzey, D. M. Weary, B. Y. F. Tiau, and M. A. G. von Keyserlingk ${ }^{1}$ \\ Animal Welfare Program, Faculty of Land and Food Systems, University of British Columbia, 2357 Main Mall, Vancouver, BC, V6T 1Z4, Canada
}

\begin{abstract}
The objective of this study was to determine if data derived from a system that electronically monitors feeding behavior could be used to identify competitive interactions of dairy cows at the feed bunk. A short interval between successive feeding events of 2 cows at 1 feed bin was predicted to be associated with a competitive replacement: when one cow displaced a feeding cow and then took her position at the bin. To identify the interval between feeding events that best predicted these replacement events, the feeding activity of 5 Holstein dairy cows was monitored using an electronic feeding system and video recordings. The number of times a cow was replaced at the feed bunk over 3 consecutive 24 -h periods was determined using video analysis and these events were paired with the corresponding feeding events recorded by an electronic feeding system (Roughage Intake Control system; Insentec B.V., Marknesse, the Netherlands). A pooled analysis of all 5 cows showed that the optimal interval for predicting replacements at the feed bunk was $26 \mathrm{~s}$ ( sensitivity $=86 \%$ and specificity $=82 \%$ ); this interval was termed the replacement criterion. This criterion was then applied to feeding data from a sample of 24 independent Holstein dairy cows, each observed for 3 $\mathrm{d}$ during the week following calving. Video had previously been used to measure the number of times each cow was an actor and reactor of a displacement (when one cow displaced a feeding cow but did not necessarily take her position at the bin). Despite the differences in measures, the number of replacements (as estimated by our algorithm) was positively correlated with the number of displacements [as measured using video; correlation coefficient $(\mathrm{r})=0.63$ as actor, $\mathrm{r}=0.69$ as reactor]. Estimates of an index of success in competitive interactions (number of times actor/number of times actor + number of times reactor) generated using the 2 methods were highly correlated $(\mathrm{r}=0.94)$. These results suggest that competitive behavior at the feed
\end{abstract}

Received August 28, 2013.

Accepted January 22, 2014.

${ }^{1}$ Corresponding author: nina@mail.ubc.ca bunk can be automatically quantified using data derived from an electronic feeding system.

Key words: animal welfare, feeding behavior, displacement

\section{Short Communication}

Social competition at the feed bunk (for example, when one cow makes contact or threatens a feeding cow such that a feeding cow leaves the bunk) is common among group-housed dairy cattle. This competition is known to increase in response to overstocking (Huzzey et al., 2006; Proudfoot et al., 2009) and during the first few days after regrouping (von Keyserlingk et al., 2008). Increased competition among cattle at the feed bunk is also associated with increased physiological stress (Friend et al., 1979; Huzzey et al., 2012), decreased feeding time (Olofsson 1999; Huzzey et al., 2006), and decreased DMI (Proudfoot et al., 2009).

Conventional techniques used to record competition involve live observation or retrospective observation using video recordings (e.g., Phillips and Rind, 2001; Færevik et al., 2010; Huzzey et al., 2012). These methods are time consuming and can be subject to poor intra- and interobserver reliability if the behavioral definition is poor or observer training insufficient. Identifying faster and more objective ways to measure competitive behavior at the feed bunk would be useful.

Technology has proven useful for monitoring the feeding behavior of cattle (Sowell et al., 1998; DeVries et al., 2003; Chapinal et al., 2007). For example, the Insentec Roughage Intake Control system (Insentec B.V., Marknesse, the Netherlands; validated by Chapinal et al., 2007) records intake, time, and location of feeding events for group-housed dairy cows. These data can be used in several innovative ways. For example, cows at risk for disease can be identified weeks before clinical symptoms become evident based on changes in daily feeding time and DMI (Huzzey et al. 2007; Goldhawk et al. 2009). However, no attempt has been made to use this type of data to quantify competitive behavior.

We hypothesized that competitive replacements at the feed bunk, defined as occurring when one cow (the actor) makes physical contact with a feeding cow (the 
reactor), such that reactor leaves the feed bunk and the actor takes her position, can be assessed using data derived from a system that electronically monitors feeding behavior. If the replacement is motivated by hunger, it is expected that an actor will quickly occupy the feeding location that the reactor just left. We predicted that a short interval between the feeding events of 2 different cows at 1 feed location (i.e., a short period of time during which the bin is empty between feeding events) would be linked to a replacement. The objectives of this study were (1) to determine the interval between feeding events of 2 cows at 1 bin (replacement criterion) that best predicts replacement events as identified by video analysis and (2) validate the use of this replacement criterion by correlating estimates of competitive behavior obtained using video analysis and the electronic feeding system from a larger sample of animals.

To achieve our first objective, the feeding and competitive behavior of 5 pregnant, nonlactating, Holstein dairy cattle [heifers $(\mathrm{n}=2)$, first lactation $(\mathrm{n}=2)$, second lactation $(\mathrm{n}=1)$ ] were observed concurrently during 3 consecutive 24-h periods at The University of British Columbia Dairy Education and Research Center (Agassiz, British Columbia, Canada). The selected sample size was limited to 5 cows during this initial analysis because of the time investment required to record competitive behavior from video recordings. These cows were part of a group of 20 cows housed in a pen containing 12 electronic feed bins (Insentec B.V.). Each feed bin measured $1.00 \mathrm{~m}$ wide, $0.75 \mathrm{~m}$ high, and 0.84 $\mathrm{m}$ deep. All 20 cows in the pen had access to all feed bins and ad libitum access to 2 water bins. Cows were fed a TMR formulated for nonlactating cows, consisting of $21.3 \%$ corn silage, $42.8 \%$ alfalfa hay, and $35.9 \%$ concentrate and mineral mix on a DM basis.

Cows were fitted with an ear tag transponder (HighPerformance ISO Half Duplex Electronic ID Tag; Allflex Canada, Saint-Hyacinthe, Quebec, Canada). When a cow approached a feed bin, an antenna detected the cow's transponder, allowing a gate to drop, providing the cow access to the feed. The electronic feeding system recorded the time the cow entered the bin and the initial weight of the feed bin at the time of entry and then the time the cow left the feed bin and the weight of the bin at the time of exit; thus, for each visit to a feed bin, the system would record the duration of the visit and the amount of feed consumed.

Competitive behavior of the focal cows was monitored using video cameras [closed-circuit television (CCTV) camera, model WV-BP330; Panasonic Corp., Osaka, Japan] fitted with an F1.4/2.5-6-mm varifocal lens. Cameras were connected to a video multiplexer (Panasonic Video Multiplexer, WJ FS 416) and a time- lapse videocassette recorder (Panasonic Time-Lapse VCR, AG-6540). Two cameras were spaced evenly and directly above the feed bunk. Red lights $(100 \mathrm{~W})$ were hung adjacent to the cameras to facilitate video recording at night. Individual cows were identified on the video recordings by unique alphanumeric symbols located on their back and sides. A displacement from the feed bunk was noted when a cow's head (actor) came in contact with a cow who was feeding (reactor), such that the feeding cow withdrew its head from the feed bunk. A displacement was identified as a replacement when the actor was the next cow to begin a feeding event at the bin that the reactor was displaced from.

For each feeding event, the elapsed time where the bin was unoccupied immediately following the event was noted. Each interval was then coded as being associated with a replacement (1) or not (0) based on the video analysis.

The logistic procedure of SAS (version 9.3; SAS Institute Inc., Cary, NC) was used to determine the predicative value of the interval between feeding events of 2 cows at 1 bin for identifying a replacement event. Replacement outcome (0 vs. 1) was considered the dependent variable and interval between feed events as the independent variable in the model. A receiver operating characteristic (ROC) curve was constructed and area under the curve (AUC) was determined as a measure of accuracy in predicting replacements. An ROC curve is a plot of the true-positive rate (sensitivity) versus the false-positive rate $(1$ - specificity), for a binary classifier (i.e., replacement outcome) for all possible discrimination thresholds (i.e., intervals between feed events). Sensitivity (Se) is the proportion of intervals at or below a given threshold that are associated with true replacement events, whereas specificity (Sp) is the proportion of intervals above a given threshold that are not associated with true replacement events. The point on an ROC curve that is closest to the upper left corner has the highest combined Se and Sp, and was considered the optimal threshold (Akobeng, 2007; Dohoo et al., 2009) and was termed the replacement criterion. Because this analysis requires that the interval be used as the experimental unit, replacement criteria were determined for each cow individually $(\mathrm{n}=$ 5) and then for all cows together.

Based on the video analysis, the 5 focal cows were replaced at the feed bunk a total of 160 times over the 3 -d observation period and had a total of 627 feeding events. Table 1 presents the replacement criteria and associated statistics using data from individual cows and from all the cows combined. Estimates of the individual replacement criteria varied (range of 15 to 47 s); however, these estimates were generally associated with high Se and Sp. In all cases, the exact 2-sided 
Table 1. Optimum replacement criteria (s; defined as the interval threshold with the highest combined sensitivity and specificity in the receiver operating characteristic curve) and related statistics, to discriminate if a cow was replaced at the feed bunk ${ }^{1}$

\begin{tabular}{lcccccc}
\hline Cow & $\begin{array}{c}\text { No. of } \\
\text { intervals }\end{array}$ & $\begin{array}{c}\text { No. of } \\
\text { replacements }\end{array}$ & $\begin{array}{c}\text { Replacement } \\
\text { criterion }(\mathrm{s})\end{array}$ & $\begin{array}{c}\mathrm{Se}^{2} \\
(95 \% \mathrm{CI})\end{array}$ & $\begin{array}{c}\mathrm{Sp}^{3} \\
(95 \% \mathrm{CI})\end{array}$ & $\begin{array}{c}\mathrm{AUC}^{4} \\
(95 \% \mathrm{CI})\end{array}$ \\
\hline Pooled & 627 & 160 & 26 & $86(80-91)$ & $82(78-86)$ & $0.89(0.86-0.92)$ \\
Individual & & & & & & \\
Cow 1 & 129 & 10 & 35 & $90(56-100)$ & $82(73-88)$ & $0.87(0.76-0.99)$ \\
Cow 2 & 135 & 52 & 25 & $89(77-96)$ & $75(64-84)$ & $0.83(0.77-0.91)$ \\
Cow 3 & 136 & 33 & 47 & $88(72-97)$ & $81(72-88)$ & $0.90(0.85-0.96)$ \\
Cow 4 & 131 & 35 & 15 & $83(66-93)$ & $90(82-95)$ & $0.90(0.83-0.96)$ \\
Cow 5 & 96 & 30 & 23 & $93(78-99)$ & $82(70-90)$ & $0.88(0.86-0.95)$ \\
\hline
\end{tabular}

${ }^{1}$ Criteria were estimated separately for each cow and also using the pooled data of all 5 cows.

${ }^{2}$ Sensitivity (Se) is the proportion of intervals at or below replacement criterion that was associated with true replacement events (true positives) and the Fisher exact 95\% CI for the Se.

${ }^{3}$ Specificity $(\mathrm{Sp})$ is the proportion of intervals above the replacement criterion that was not associated with true replacement events (true negatives) and the Fisher exact 95\% CI for the Sp.

${ }^{4}$ Area under the curve (AUC) was determined from the receiver operating characteristic curves [Se vs. $(1-\mathrm{Sp})$ ] as a measure of accuracy in predicting replacements using the optimum replacement criterion. If $\mathrm{AUC}=0.5$, the predictive value is no better than flipping a coin.

tests of the null hypothesis that Se or $\mathrm{Sp}=0.5$, were significant $(P \leq 0.02)$, indicating that these Se and Sp values were not due to chance. Further, AUC estimates for the pooled and individual data were similar and in all cases different from $\mathrm{AUC}=0.5(P<0.001)$, suggesting that the replacement criterion was able to identify replacement events better than chance alone.

To further validate the pooled replacement criterion, it was applied to electronically derived feeding data from a sample of 24 Holstein dairy cows ( 8 primiparous and 16 multiparous cows) to quantify replacement behavior. The previous literature has focused almost exclusively on displacements (rather than replacements); to better position our results within this literature, we scored displacement behavior from video and then correlated this to the replacement behavior that can be estimated using our criterion developed in the first part of this study. As described earlier, displacements, by definition, do not require that the actor enter the feed bin from which the reactor had been feeding. Our aim was to determine if an electronically derived estimate of competitive behavior (i.e., replacements) would correlate well with conventional methods of estimating competitive behavior (i.e., displacements from video analysis). Each cow was followed at different times (during $3 \mathrm{~d}$ within the week following their respective calving date) and, therefore, within different group compositions. Data were collected at The University of British Columbia Dairy Education and Research Center over a 5-mo period. These cows were part of a larger transition cow study (Huzzey et al., 2007). Pen stocking density was maintained at 20 cows with access to 12 electronic feed bins and 2 water bins. Cows were fed a lactating cow TMR consisting of $21.3 \%$ grass silage, $14.7 \%$ corn silage, $12.3 \%$ alfalfa hay, and $51.7 \%$ concentrate and mineral mix on a DM basis.

Video cameras were used to record displacements at the feed bunk as described and defined earlier. The number of times the cow was an actor and reactor of a displacement was recorded. For each cow, an index of success in competitive interactions was also determined by dividing the number of times a cow was an actor by the total number of times she was an actor and reactor (total interactions). This competition index has been used previously to reflect the social status of each cow according to her experiences in agonistic interactions (Galindo and Broom 2000; Val-Laillet et al., 2008).

Feeding activity was recorded by the electronic feeding system as previously described. For each individual feeding event undertaken by a cow, the elapsed time where the bin was unoccupied immediately following her feeding event was noted (interval linked to being the reactor of a possible replacement) and the period of time the bin was not occupied before her feeding event was noted (interval linked to being the actor of a possible replacement; Figure 1). Using the pooled replacement criterion identified in the first part of this study $(\leq 26 \mathrm{~s})$ the total number of times a cow was an actor and reactor of a replacement was determined from the electronic feed data and, using this information, each cows' index of success in competitive interactions was determined.

Using the CORR procedure of SAS (version 9.3), Pearson correlation coefficients were used to evaluate how the frequency of replacements (actor/reactor) and index of success, calculated using the electronic feeding system and replacement criterion $(\leq 26 \mathrm{~s})$, correlated with frequency of displacements (actor/reactor) and index of success calculated using video analysis. 


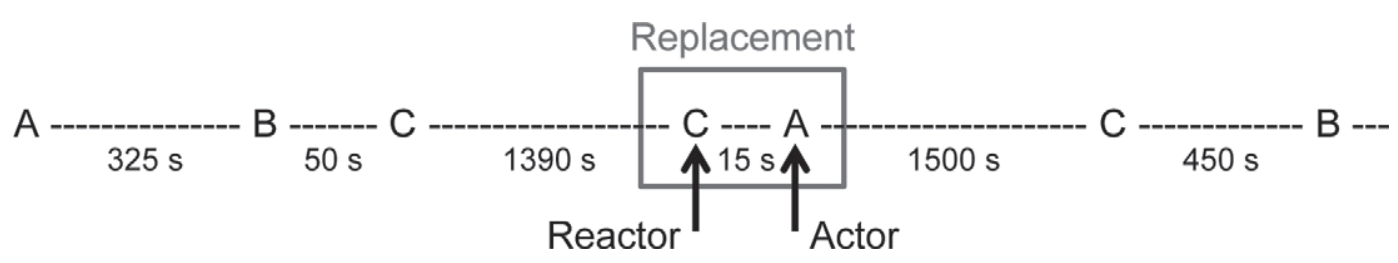

Figure 1. A theoretical representation of the feed bunk visit pattern of 3 cows (A, B, and C) at 1 feed bin. The dashed line represents the feed intervals (period of time the bin was empty between the visits of 2 cows) and feed bunk visits are represented by the letters inserted into the timeline. In this scenario, A (actor) replaces $\mathrm{C}$ (reactor) once. The interval between the feeding events of these 2 cows is the replacement interval with the animal feeding before and after characterized as being the reactor and actor, respectively.

A positive correlation was observed between the number of times a cow was an actor in a replacement (calculated electronically) and the number of times she was an actor in a displacement (calculated from video analysis; $\mathrm{r}=0.63 ; P=0.001$; Figure $2 \mathrm{~A}$ ). Similarly, a positive correlation existed between the number of times a cow was the reactor of a replacement (electronic) and reactor of a displacement (video; $\mathrm{r}=0.69$; $P<0.001$; Figure 2B). Finally, estimates of the index of success calculated electronically using the replacement criterion were strongly correlated with estimates calculated from video analysis $(\mathrm{r}=0.94 ; P<0.001$; Figure 2C).

This is the first study to show that competitive behavior at the feed bunk in dairy cattle can be measured using an electronic feed monitoring system. Using a replacement criterion of $\leq 26 \mathrm{~s}$ (interval between the feeding events of 2 different cows at the same feed location), the number of times a cow was replaced could be predicted with $86 \%$ Se and $82 \%$ Sp. Although this initial analysis used a small sample size, further analysis revealed that the pooled replacement criterion $(\leq 26 \mathrm{~s})$ has some external validity. Using a larger and independent sample of cattle housed within groups of variable composition (but constant in stocking density), this secondary analysis showed that electronically derived estimates of replacement behavior were correlated with estimates of displacement behavior obtained from video. To improve the external validity of the replacement criterion, future work should examine replacement behavior under a range of feeding management practices and pen designs.

As with all predictive tests, our replacement criterion did result in some misclassification. In the first part of this study, 22 out of the total 160 true replacements (14\%) were not identified using the replacement criterion (i.e., the replacement intervals was greater than 26 $\mathrm{s}$; the longest interval was $21 \mathrm{~min}$ ). Long replacement intervals between feeding events were more common at night (2000 to $2300 \mathrm{~h}$ ) or during periods of low bunk occupancy (1000 to $1200 \mathrm{~h}$ ). These events were likely not motivated by hunger, and instead may be related to a dominant cow defending specific feeding locations from subordinates (Mendl and Held, 2001).

The replacement criterion only identifies displacements that are followed by a replacement at the feed bunk and, therefore, displacement where the actor does not replace the reactor would not be identified. Thus, the use of the replacement interval criterion will underestimate the total number of competitive interactions a cow is involved in (see Figure 2). However, as can be seen from Figure 2C, estimates of the competition index of success were not highly influenced by nonreplacement displacements, as this measure is relative to the total number of each type of interaction.

Previous work has demonstrated that electronic feeding systems can generate data that is correlated to the social status of animals. For example, Hoy et al. (2012) found that data from an electronic feeding station could be used to describe the individual social rank of pigs; high-ranking animals (more often successful in agonistic encounters) made fewer visits to the electronic feeder during a 48-h period, stayed at the feeder for a longer duration at each visit and consumed more feed during each visit compared with low-ranking cows. Similar relationships have been observed in cattle. For example, Zobel et al. (2011) found a positive correlation in beef heifers between success in agonistic interactions and DMI, time spent at the bunk, and number of feed bunk visits. Hoy et al. (2012) and Zobel et al. (2011) used video analysis to assess competitive behavior and then used these measures to describe social rank. The current study is the first to use the electronic data generated from a feeding system to measure a competitive behavior (replacements). Our work will allow users of electronic feeding systems to easily estimate replacements and, thus, social status. We encourage other users to consider this approach when assessing housing and management factors thought to affect competitive behavior in cattle.

Calculating replacement frequency using automated methods not only eliminates the need for time-consuming video analysis in research, but also may provide opportunities for real-time on-farm assessments of com- 



Figure 2. The relationship between replacement frequency obtained from the electronic feeding system (replacement criterion $\leq 26$ $\mathrm{s})$ and displacement frequency obtained from direct observation of video recordings, for 24 cows, shown separately for (A) the number of times cow was actor and (B) the number of times cow was reactor. Panel $\mathrm{C}$ shows the relationship between replacement frequency and index of success in competitive interactions [no. of times actor/(no. of times actor + no. of times reactor $)]$. petitive behavior as a management tool. For example, cows that are less competitive at the feed bunk during the week before calving are at increased risk for disease after calving (Huzzey et al., 2007). In overstocked group pens, cows that are less successful in competitive interactions have changes in energy metabolism that may increase their risk for disease (Huzzey et al., 2012). Identifying these animals sooner using automated methods may be important for improving overall herd health.

The electronic feeding system used in this study is not a practical option for monitoring the feeding behavior of cows by the average commercial dairy producer due to the high costs and labor associated with this system. However, our approach to electronically deriving estimates of competitive behavior using the replacement criterion could likely also be used with simplified electronic feed monitoring systems that measure only feeding time and cow location along the bunk using radio frequency identification technology.

In conclusion, this is the first study to show that data derived from an electronic feeding system can be used to directly quantify social competition in dairy cattle at the feed bunk. Short intervals ( $\leq 26 \mathrm{~s})$ between successive feeding events of 2 cows at 1 feed bin were associated with competitive replacements (when one cow displaced a feeding cow and took her position at the feed bunk). The frequency of competitive replacements calculated using this criterion was also well correlated with displacement frequency calculated using conventional video analysis.

\section{ACKNOWLEDGMENTS}

The authors thank all of the staff and student support at the University of British Columbia (UBC) Dairy Education and Research Centre (Agassiz, BC, Canada) and, in particular, Victor Chan for his help with the video analysis of displacement behavior. The UBC Animal Welfare Program is funded through the Natural Sciences and Engineering Research Council of Canada (NSERC) Industrial Research Chair program, with industry contributions from the Dairy Farmers of Canada (Ottawa, ON, Canada), Westgen Endowment Fund (Milner, BC, Canada), Zoetis Canada (Kirkland, QC, Canada), BC Cattle Industry Development Fund (Kamloops, BC, Canada), the BC Milk Producers (Burnaby, BC, Canada), BC Dairy Foundation (Burnaby, BC, Canada), BC Dairy Education and Research Association (Abbotsford, BC, Canada), and Alberta Milk (Edmonton, AB, Canada).

\section{REFERENCES}

Akobeng, A. K. 2007. Understanding diagnostic tests 3: Receiver operating characteristic curves. Acta Paediatr. 96:644-647. 
Chapinal, N., D. M. Veira, D. M. Weary, and M. A. G. von Keyserlingk. 2007. Technical note: Validation of a system for monitoring individual feeding and drinking behavior and intake in grouphoused cattle. J. Dairy Sci. 90:5732-5736.

DeVries, T. J., M. A. G. von Keyserlingk, D. M. Weary, and K. A. Beauchemin. 2003. Validation of a system for monitoring feeding behavior of dairy cows. J. Dairy Sci. 86:3571-3574.

Dohoo, I., W. Martin, and H. Stryhn. 2009. Veterinary Epidemiologic Research. AVC Inc., Charlottetown, PEI, Canada.

Færevik, G., M. B. Jensen, and K. E. Bøe. 2010. The effect of group composition and age on social behavior and competition in groups of weaned dairy calves. J. Dairy Sci. 93:4274-4279.

Friend, T. H., F. C. Gwazdauskas, and C. E. Polan. 1979. Change in adrenal response from free stall competition. J. Dairy Sci. 62:768-771.

Galindo, F., and D. M. Broom. 2000. The relationships between social behaviour of dairy cows and the occurrence of lameness in three herds. Res. Vet. Sci. 69:75-79.

Goldhawk, C., N. Chapinal, D. M. Veira, D. M. Weary, and M. A. G. von Keyserlingk. 2009. Prepartum feeding behavior is an early indicator of subclinical ketosis. J. Dairy Sci. 92:4971-4977.

Hoy, S., S. Schamun, and C. Weirich. 2012. Investigations on the feed intake and social behaviour of fattening pigs fed at an electronic feeing station. Appl. Anim. Behav. Sci. 139:58-64.

Huzzey, J. M., T. J. DeVries, P. Valois, and M. A. G. von Keyserlingk. 2006. Stocking density and feed barrier design affect the feeding and social behavior of dairy cattle. J. Dairy Sci. 89:126-133.

Huzzey, J. M., R. J. Grant, and T. R. Overton. 2012. Short communication: Relationship between competitive success during displacements at an overstocked feed bunk and measures of physiology and behavior in Holstein dairy cattle. J. Dairy Sci. 95:4434-4441.
Huzzey, J. M., D. M. Veira, D. M. Weary, and M. A. G. von Keyserlingk. 2007. Prepartum behavior and dry matter intake identify dairy cows at risk for metritis. J. Dairy Sci. 90:3220-3233.

Mendl, M., and S. Held. 2001. Living in groups: An evolutionary perspective. Pages 7-36 in Social Behavior of Farm Animals. L. J. Keeling and H. W. Gonyou, ed. CABI Publishing, UK.

Olofsson, J. 1999. Competition for total mixed diets fed for ad libitum intake using one or four cows per feeding station. J. Dairy Sci. 82:69-79.

Phillips, C. J. C., and M. I. Rind. 2001. The effects on production and behavior of mixing uniparous and multiparous cows. J. Dairy Sci. 84:2424-2429.

Proudfoot, K. L., D. M. Veira, D. M. Weary, and M. A. G. von Keyserlingk. 2009. Competition at the feed bunk changes the feeding, standing, and social behavior of transition dairy cows. J. Dairy Sci. 92:3116-3123.

Sowell, B. F., J. G. P. Bowman, M. E. Branine, and M. E. Hubbert. 1998. Radio frequency technology to measure feeding behavior and health of feedlot steers. Appl. Anim. Behav. Sci. 59:227-284.

Val-Laillet, D., A. M. de Passillé, J. Rushen, and M. A. G. von Keyserlingk. 2008. The concept of social dominance and the social distribution of feeding-related displacements between cows. Appl. Anim. Behav. Sci. 111:158-172.

von Keyserlingk, M. A. G., D. Olenick, and D. M. Weary. 2008. Acute behavioral effects of regrouping dairy cows. J. Dairy Sci. 91:10111016

Zobel, G., K. S. Schwartzkopf-Genswein, B. M. A. Genswein, and M. A. G. von Keyserlingk. 2011. Impact of agonistic interactions on feeding behaviours when beef heifers are fed in a competitive feeding environment. Livest. Sci. 137:1-9. 